ology,' edited by V. Zachary Cope. This volume is of clinical importance, including the experience of both the fighting and civilian services, whilst later volumes will relate to these services separately recorded.

As with all such books the Editor has rightly called upon a large number of authorities in compiling his important production. He has had a very important Editorial Committee and the assistance of well over 50 leading authorities in their subjects. Much of the early work was undertaken by Dr. Charles Newman of the Postgraduate Medical School, to whom great credit is due, and fullest praise must be given to Dr. Cope for his fine editorial work.

The scope of this volume is too great for individual comment, but it rightly includes much vital factual information and describes the astounding achievements in medicine and pathology during the war. Not only does this book appeal to all medical men but much of the astounding therapeutic advancements described in it are of great interest to many non-medical readers.

It would be invidious to pick out any special chapter of the 33 included for special comment, but it can be fairly agreed that no branch of medicine has been forgotten and there is interest in every page of this fascinating volume.

\section{THE SCIENCE AND ART OF JOINT MANIPULATION}

\section{Vol. II: The Spinal Column}

By James Mennell, M.A., M.D., B.C. Pp. vii + 264, with 148 illustrations, many in colour. London: J. \& A. Churchill, Ltd. 1952. £2 $2 \mathrm{~s}$.

This book is a monograph on backache and associated disorders embracing an earlier book, 'Backache,' by the same author. It presents the case for the sacroiliac joint as the commonest cause of backache in the lumbar region.

Diagnosis occupies a large proportion of the book and the section on treatment includes many physical methods other than manipulation.

It is copiously illustrated with 148 sketches, line drawings and X-ray photographs.

The author's long fight for the rational use of manipulation by the medical profession is at last nearing victory and the methods described and illustrated in this work are all well tried and effective. His accumulated observation and wisdom make this book one which should be read by all who have to deal with cases of backache.

\section{BRITISH ENCYCLOPAEDIA OF MEDICAL PRACTICE}

Edited by The RT. HoN. LoRD HORDER, G.C.V.O., M.D., F.R.C.P. 2nd Edition. Vols. 9 and 10. Pp. xvi +659 , with 158 illustrations, and $x v+$ 7I 8, with II 7 illustrations respectively. London: Butterworth \& Co., Ltd. 1952. 65s. per vol.

In the present edition of these two volumes almost half the sections have been rewritten or brought up to date by new contributors. Most of the chapters remain under their old headings, but some have fallen by the wayside-for example, Hereditary Oedema, Mucous Colic and Resuscitation. Important new sections have been included: a good account by Dr. Bodley Scott of Myelomatosis, which now occupies a chapter in its own right, is a reminder that this disease, although uncommon, is by no means rare. A well-illustrated section on diagnostic measures in Orthopaedic Surgery by Mr. Leon Gillis will be generally welcomed. The notable advances that have been made in psychological medicine in the past decade are reflected principally by the concise account of Electroconvulsive therapy by Dr. J. G. Hamilton.

Dr. A. J. Capriani contributes a valuable chapter on radioactive isotopes. This section underlines more boldly than any other, not only the remarkable advances in medical knowledge that have been made since 1938 when the first edition of the present work was published-and, incidentally, when nuclear fission was discovered-but also the magnitude of the task which is being so well accomplished by Lord Horder and his gallant band of editors and contributors in bringing the present edition so thoroughly up to date.

D.S.L.

\section{THE FOOT}

By Norman C. LaKe, M.D., M.S., D.Sc., F.R.C.S. 4th Edition. Pp. vi +466 , with 166 illustrations. London: Baillière, Tindall \& Cox. 1952. 253.

In the preface to this fourth edition of his book the author states that the aim remains unchanged'... to deal with those conditions which come within the purview of the practitioner and general surgeon, omitting major orthopaedic procedures, and to provide a volume which will be of value to the chiropodist, physiotherapist and other medical auxiliaries ....'

The book may be recommended for its informative and thought-provoking discussion of the aetiology (including evolutionary factors) and the pathology of foot disorders, and it should be read for a better understanding of the foot and its: problems.

One entirely agrees with the author that '... the complete diagnosis of a troublesome foot case consists not merely in the pigeon-holing of the condition actually found upon examination, but in reading into the case its complete history from the commencement of the aetiological factors ...'

Treatment, however, is not always presented with the clarity which a student might desire, and there are instances where the advice given might be criticized by orthopaedic surgeons, for example, astragalectomy for sub-astragaloid dislocations, and fracture of the astragalus, and excision of the sesamoids in operations for hallux vagus.

The volume is well printed and illustrated, but it might seem regrettable that the opportunity was not taken to modernise the anatomical terminology to the New English nomenclature.

J.G.T. 